\title{
A case of severe hypercalcaemia caused by hyperthyroidism with concomitant adrenal insufficiency
}

\author{
J Sabin, H Coakley, A Evans \\ Department of Diabetes and Endocrinology, Cheltenham General Hospital
}

Hypercalcaemia is a recognised feature of hyperthyroidism due to accelerated bone turnover caused by thyroid hormone. When present, it is generally mild, usually with levels $<3 \mathrm{mmol} / \mathrm{l}$.

We present a case of a 19 year old male with thyrotoxicosis, who had severe hypercalcaemia and was also found to have co-existent adrenal insufficiency.

DAY 1

A 19 year old student presented with a four month history of weight loss, anxiety, tremors and palpitations

On examination he was clinically thyrotoxic with a tremor, heart rate of $114 \mathrm{bpm}$ but no goitre.

\begin{tabular}{|c|c|}
\hline $\mathrm{fT} 4$ & $>95 \mathrm{pmol} / \mathrm{l}$ \\
\hline $\mathrm{fT} 3$ & $>30 \mathrm{pmol} / \mathrm{l}$ \\
\hline $\mathrm{TSH}$ & $<0.05 \mathrm{mIU} / \mathrm{l}$ \\
\hline $\mathrm{Ca} 2+$ & $3.4 \mathrm{mmol} / \mathrm{l}$ \\
\hline
\end{tabular}

He was admitted to hospital and commenced on IV fluids, carbimazole and propanolol.

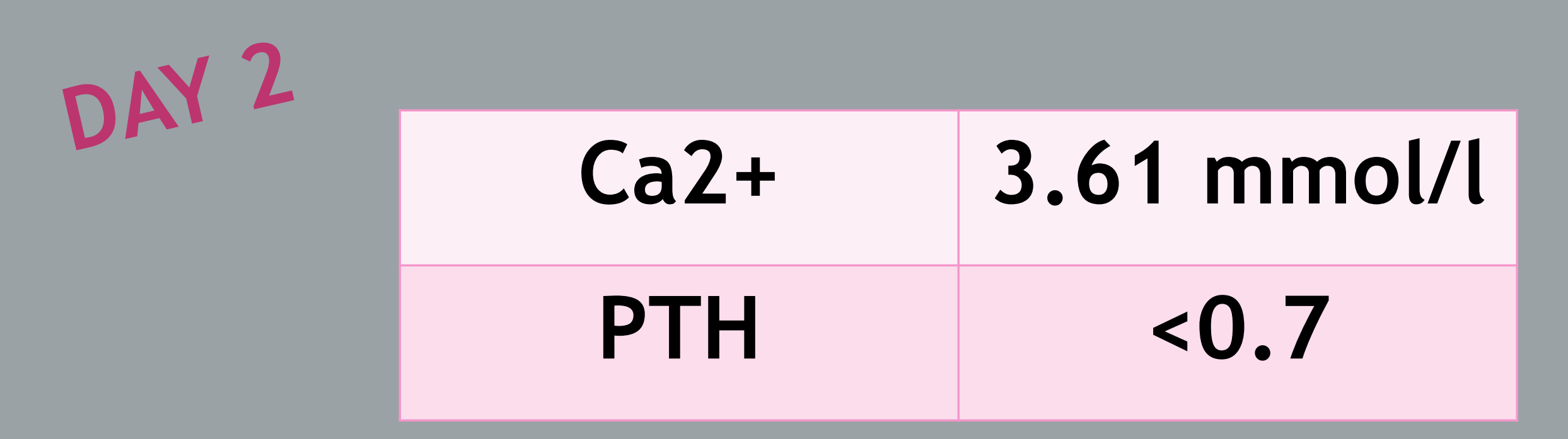

As his PTH was suppressed completely, the significant hypercalcaemia was likely due to severe thyrotoxicosis. He received IV pamidronate treatment as his calcium levels rose despite adequate fluid replacement

\section{DAY 3 +}

He developed pyrexia, tachycardia, hypertension and increased agitation. This was managed as a thyrotoxic crisis with propylthiouracil, iodine solution and hydrocortisone.

There was a significant clinical improvement within 48 hours. His goitre had also became more apparent.

He subsequently developed rebound hypocalcaemia and was started on Adcal supplements, which were later stopped one month later in clinic. His calcium levels have remained within the normal range since then.
Adrenal

Adrefficiency

A 9am cortisol level prior to starting steroids was $117 \mathrm{mmol} / \mathrm{l}$. He underwent a series of short synacthen tests

\begin{tabular}{|l|c|c|c|}
\hline & $\begin{array}{c}1 \\
\text { week }\end{array}$ & $\begin{array}{c}3 \\
\text { months }\end{array}$ & $\begin{array}{c}5 \\
\text { months }\end{array}$ \\
\hline $\begin{array}{l}\text { Cortisol }(\mathrm{mmol} / \mathrm{l}) \\
0 \text { mins }\end{array}$ & 195 & 113 & 267 \\
\hline $\begin{array}{l}\text { Cortisol }(\mathrm{mmol} / \mathrm{l}) \\
30 \text { mins }\end{array}$ & 247 & 433 & 541 \\
\hline fT4 $(\mathrm{pmol} / \mathrm{l})$ & $>95$ & 25 & 8.5 \\
\hline fT3 $(\mathrm{pmol} / \mathrm{l})$ & $>30$ & 12.9 & 3.4 \\
\hline TSH $(\mathrm{mlU} / \mathrm{l})$ & $<0.05$ & 0.05 & 0.07 \\
\hline
\end{tabular}

\section{Follow up}

He has been on a reducing course of propylthioruacil with gradual improvement in his thyroid function. Anti-TPO antibodies were negative.

Hydrocortisone replacement was stopped following the third short synacthen test.

\section{Discussion}

Hypercalcaemia caused by thyrotoxicosis is usually mild.

Thyroid hormone increases bone turnover and mobilisation of calcium from bone. Cortisol exerts an antagonistic effect to this, increasing renal calcium excretion and reducing intestinal absorption. Cortisol deficiency with hyperthyroidism, can therefore lead to increased hypercalcaemia.

Thyroid hormones are known to increase cortisol clearance and thyrotoxicosis leads to increased cortisol secretion. The theory has been suggested that in sustained thyrotoxicosis, the adrenal glands are secreting at their maximum capacity. Their reserve for a response to additional stimulation with ACTH is therefore diminished, giving a picture of relative adrenal insufficiency.

We postulate that this young man had relative adrenal insuffiency caused by severe thyrotoxicosis, which has now resolved with treatment of the hyperthyroidism. This case has highlighted the need to consider thyrotoxicosis as a cause of severe hypercalcaemia and also to consider the role of cortisol within this and other cases of severe thyrotoxicosis. 